\title{
ASSESSMENT OF CHROMATOGRAPHIC SEPARATIONS FOR ANTIHYPERTENSIVE AND ANTIDIABETIC DRUGS
}

\begin{abstract}
SOWMYALAKSHMI VENKATARAMAN ${ }^{1 *}$, HARITHA $G^{2}$
${ }^{1}$ Department of Pharmaceutical Chemistry and Analysis, School of Pharmaceutical Sciences, Vels Institute of Science, Technology and Advanced Studies (VISTAS), Pallavaram, Chennai, Tamil Nadu, India. ${ }^{2}$ Research Scholar, Department of Pharmaceutical Chemistry and Analysis, School of Pharmaceutical Sciences, Vels Institute of Science, Technology and Advanced Studies (VISTAS), Pallavaram, Chennai, Tamil Nadu, India. Email: sowmyamahesh30@gmail.com
\end{abstract}

Received: 10 October 2018, Revised and Accepted: 11 December 2018

\section{ABSTRACT}

Context: The focus of this review is to compile the different chromatographic methods that were reported earlier for the analysis of different antihypertensive and antidiabetic drugs.

Objective: The magnitude of chemical entities investigated and entering into the medicinal field for various health-related ailments is escalating year after year. The drugs are either innovative entities or fractional structural variation of the preexisting chemical molecule. These drugs may exhibit unexpected toxicities after Phase IV of clinical trials, resulting in their withdrawal from the market. Under these circumstances, analytical measures for these drugs may not be accessible in the pharmacopeias. The main aim of this work is to compile the different analytical techniques for the quantification of various antihypertensive drugs and antidiabetic drugs.

Methods: The present work is to thoroughly study the literature for the application of different analytical techniques such as high-performance liquid chromatography (HPLC) and liquid chromatography-mass spectroscopy/tandem mass spectroscopy (LC-MS/MS) for the quantification of antihypertensive drugs and anti-diabetic drugs.

Results: The present study attempts to collate various analytical techniques that were developed and validated for the estimation of few important antidiabetic and antihypertensive drugs either in pure, individually or combined with other pharmaceutical dosage form by HPLC, LC-MS/MS, and high-performance thin-layer chromatography techniques.

Conclusion: Different chromatographic methods are considered to be rapid tools for qualitative and quantitative analysis of newer chemical entities in pharmaceuticals. The amount of these newer chemical entities which are reaching the pharmaceutical market is increasing day by day nevertheless there exists a lag in establishing the standard protocols for the identification, impurity profiling, related substance and assay method. Hence, the present review compiles the different analytical methods that were reported in the literature and thus helps the researchers and chemists to make use of the analytical techniques for the quantification and validation of various antidiabetic and antihypertensive drugs.

Keywords: Liquid chromatography, High-performance liquid chromatography, Antihypertensive, Antidiabetic, Oral hypoglycemics, Liquid chromatography-mass spectroscopy/tandem mass spectroscopy.

(c) 2018 The Authors. Published by Innovare Academic Sciences Pvt Ltd. This is an open access article under the CC BY license (http://creativecommons. org/licenses/by/4. 0/) DOI: http://dx.doi.org/10.22159/ajpcr.2018.v11s4.31701

\section{INTRODUCTION}

Nowadays, hypertension is prevalently seen among individuals across the world and is an important modifiable risk factor for various cardiovascular ailments. It ultimately affects the functioning of the heart, kidney, and brain. Antihypertensive drugs comprise vasodilators, diuretics, angiotensin receptor blockers, and sympathoplegic agents [1]. Vasodilators reduce the tension in the vascular muscle; a diuretic depletes the levels of sodium and lessens the volume of blood; angiotensin receptor blockers hinder the angiotensin-converting enzyme; and sympathoplegic agents taper off the cardiac output [2].

Elevated levels of glucose in blood and fluctuations in the levels of insulin production by the pancreas provoke the disease called diabetes mellitus. Other than insulins, oral hypoglycemics such as antidiabetic drugs comprise thiazolidinediones, biguanides, incretin-based drugs, sulfonylureas, alpha-glucosidase inhibitors, glitinides and amylin analog. All these drugs help to regulate the amount of insulin in the blood [3].

The important objective of this study is to collate the different bioanalytical techniques that are available for various drugs in the class of antihypertensives and antidiabetics. Accordingly, a thorough literature search from the PUBMED (NCBI) database using appropriate keywords was performed. Table 1 summarizes the salient features of different antihypertensive and antidiabetic drugs. The present review compiles the reported bioanalytical methods with more emphasis for approved drugs such as pioglitazone, metformin, glipizide, amlodipine, nifedipine, valsartan, and captopril.

Hence, the present manuscript is based on the various analytical method developments and validation carried out for antihypertensive and antidiabetic drugs. In this review, a detailed study on the assay, impurity profiling, and stability indication assay, bio-analytical methods that were carried out by various chromatographic methods are discussed for hypertension and diabetes drugs in their pure form, individually or in combined pharmaceutical dosage form.

Analysis involving liquid chromatography-mass spectroscopy/ tandem mass spectroscopy (LC-MS/MS)

Pioglitazone and its metabolic products (III and IV) were analyzed in the plasma using LC-MS/MS involving electrospray tandem mass spectrometer system. The drug was extracted from plasma using liquidliquid extraction (LLE) with methyl t-butyl ether:n-butyl chloride 


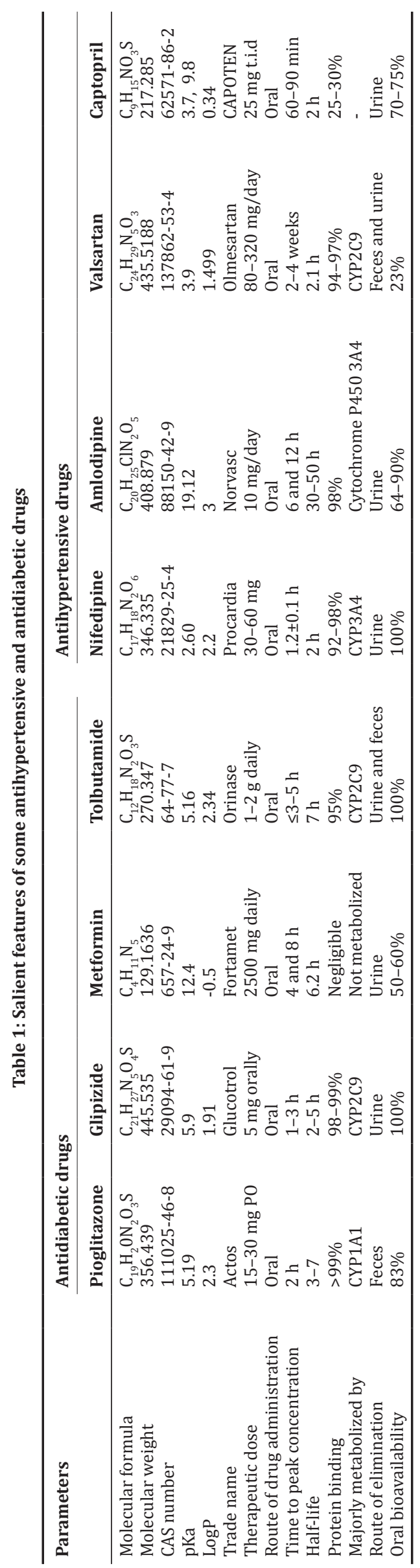

1:1 (v/v). The calibration range was found to be $0.5-2000 \mathrm{ng} / \mathrm{mL}$ [4]. Pioglitazone and candesartan were extracted from $0.1 \mathrm{~mL}$ human plasma by SP extraction with reversed phase column $\left(\mathrm{C}_{18}\right.$ column), and organic phase consists of 20:80 (v/v) formic acid $(0.1 \%)$ and acetonitrile [5]. Tolbutamide and its related substances were studied in rat plasma by sim in positive mode using $\mathrm{C}_{18}$ (Zorbax) column using $0.1 \%$ formic acid along with acetonitrile used as eluant. Extraction was achieved by liquid-liquid scheme using ethyl acetate [6]. The separation of drugs such as sitagliptin and metformin in human plasma was studied using SCX column involving biochemical partition using acetonitrile (ACN) (50):50\% of ammonium acetate buffer $(20 \mathrm{mM})$ as mobile phase, and $\mathrm{pH}$ was maintained at acidic condition during the course of analysis [7].

LC-MS study was carried out using human plasma for the determination of metformin, atorvastatin, and glimepiride [8]. The extraction was done with protein precipitation with acetonitrile. Pharmacokinetic parameters were investigated in nifedipine, montelukast, and gliclazide, and they were analyzed using SB- $\mathrm{C}_{18}$ with formic acid $(0.1 \%)$ 84:16 acetonitrile as mobile phase [9]. Analysis of sacubitril and valsartan in rat plasma was carried out using liquid chromatography, and further, the eluent was subjected for ionization by ESI in positive mode. The study was carried out using Hypersil GOLD $\mathrm{C}_{18}$ column, with acetonitrile and formic acid $(0.1 \%)$ as mobile phase. Before the analysis, the drugs were extracted using deproteinization [10]. Extraction of metformin, ramipril, and glimepiride from the plasma was performed by LLE using $50 \%$ butanol and $50 \% \mathrm{n}$-hexane, and further, separation was achieved by organic phase containing $90 \%$ of methanol and $10 \%$ of formic acid $(0.1 \%)$ in aqueous medium by ultra-performance liquid chromatography (UPLC) partition using $\mathrm{C}_{18}$ column. The eluent was further studied with multireaction monitoring tandem quadrupole mass spectrometer [11]. Hypersil GOLD C ${ }_{18}(50 \mathrm{~mm} 3.0 \mathrm{~mm}, 5 \mu \mathrm{m})$ column using $15 \%$ of ammonium formate $(5.0 \mathrm{mM})$ and $85 \%$ of acetonitrile as eluent in acidic conditions ( $\mathrm{pH} 4.5)$ was employed for the resolution of hydrochlorothiazide and lisinopril [12].

Antihypertensive ( $\beta$-blockers) and broncho agonist in plasma and urine were extracted using determined using solid phase microextraction method, and later, they were analyzed using pentafluorophenyl stationary phase and the mobile phase comprised of acetonitrile and water [13]. Telmisartan and pioglitazone were estimated using $\mathrm{C}_{18}(50 \mathrm{~mm} 4.6 \mathrm{~mm}$ $5 \mu \mathrm{m})$ column with methanol-ammonium formate $(10 \mathrm{mM})$ mixture $(9: 1, v / v)$ as eluent [14]. Healthy Chinese subjects were used for the estimation of amlodipine in human plasma [15]. Glimepiride and atorvastatin are estimated in human plasma by LCMS/MS. Extraction was performed by liquid-liquid method. The US FDA guidelines were followed for the method development and validation [16].

\section{Analysis using high-performance liquid chromatography (HPLC)}

Telmisartan and pioglitazone were simultaneously separated using ODS-3v column with $65 \%$ of ammonium dihydrogen phosphate buffer (pH 4.5) and $35 \%$ of acetonitrile as mobile phase and the retention times were found to be $2.38 \mathrm{~min}$ (telmisartan) and $3.16 \mathrm{~min}$ (pioglitazone), respectively [17]. Glimepiride, vildagliptin, and pioglitazone hydrochloride were estimated using HPLC coupled to UV detector, where the separation was achieved using Hypersil GOLD $\mathrm{C}_{18}$ reverse phase column with $45 \%$ of acetonitrile and $55 \%$ of $0.05 \mathrm{M}$ potassium dihydrogen phosphate buffer as eluent, and the retention times were found to be vildagliptin $(1.27 \mathrm{~min})$, pioglitazone hydrochloride (2.71 $\mathrm{min})$, and glimepiride (8.87 $\mathrm{min})$ respectively [18]. In another study, the separation of pioglitazone hydrochloride and glimepiride analytes was done by HPLC using reversed phase $\mathrm{C}_{18}$ (ODS) column with mobile phase potassium dihydrogen phosphate buffer $(\mathrm{pH} 3.4)$ and acetonitrile $(40: 60 \mathrm{v} / \mathrm{v})$ and the retention times were found to be $4.5 \pm 0.1 \mathrm{~min}$ (pioglitazone) and $10.0 \pm 0.1 \mathrm{~min}$ (glimepiride) [19]. In binary combination of carvedilol, glimepiride, or glibenclamide, the separation was achieved chromatographically using XDB- $\mathrm{C}_{18}$ reversed phased column using $30 \%$ of $0.2 \mathrm{M}$ phosphate buffer (pH 3.5) and 70\% of methanol as eluent using RRHT method [20]. 
Chromatographic separation and validation of the combined tablet containing atorvastatin, metformin, and glimepiride reported using $\mathrm{BEH} \mathrm{C}_{18}$ column, and eluent consists of $600 \mathrm{~mL}$ of acetonitrile $(60 \%)$ and phosphate buffer (pH 3) $400 \mathrm{~mL}$ (40\%) [21]. UPLC with PDA detector was used for the development of method and validation for metformin and telmisartan in pure solid dosage form using column $\mathrm{C}_{18}(150 \times 4.6$ ID) $5 \mu \mathrm{m}$, with sodium dihydrogen phosphate buffer $\left(\mathrm{NaH}_{2} \mathrm{PO}_{4}\right)$ :acetonitrile $(60: 40 \mathrm{v} / \mathrm{v})$ as mobile phase [22]. In another study, metformin hydrochloride, ramipril, and glimepiride were separated using mobile phase of $0.02 \mathrm{M} \mathrm{KH}_{2} \mathrm{PO}_{4}$ buffer and methanol (150:850) using Hypersil BDS $\mathrm{C}_{18}$ column [23].

The estimation of nifedipine, nateglinide, and lovastatin was achieved simultaneously by Millennium $\mathrm{C}_{18}$ column and $40 \%$ of $10 \mathrm{mM}$ phosphate buffer $(\mathrm{pH} 3.5)$ and $60 \%$ acetonitrile as eluent [24]. Estimation of antihypertensive and antidiabetic drugs using RP-HPLC separation was achieved by organic and aqueous phase (60:40, v/v) [25]. Degradation studies of valsartan were performed using isocratic HPLC method with $\mathrm{C}_{18}$ reverse stationary phase, with $70 \%$ methanol and $30 \%$ water ( $\mathrm{pH} 7.2$ ) as mobile phase was used in acid hydrolysis stability-indicating assay [26]. Analysis of glibenclamide, metformin, captopril, and pioglitazone in API was reported with $70 \%$ methanol and $30 \%$ water using Hypersil ODS $\mathrm{C}_{18}$ column [27]. Glibenclamide, amlodipine, atorvastatin, and metformin in human plasma were separated and validated by HPLC-UV method [28]. Antidiabetic and antihypertensive drugs were studied for stability indicating assay using RP HPLC method; the separation was achieved isocratically on a $\mathrm{C}_{18}$ column [29]. In a similar study, the combination of metformin and telmisartan was analyzed and validated by RP-HPLC method in bulk and in formulations [30].

The estimation of metformin hydrochloride, glimepiride, and atorvastatin calcium was carried out simultaneously in bulk and combined dosage form by stability indicating RP-HPLC technique [31]. Telmisartan and metformin hydrochloride were estimated by RP-HPLC method in bulk and synthetic mixture [32]. The interaction of nifedipine and metformin in hypertension with type II diabetic patients was studied using ODS Hypersil column $\mathrm{C}_{18}$, using acetonitrile, $25 \mathrm{mM}$ $\mathrm{KH}_{2} \mathrm{PO}_{4}$, and methanol as eluents [33].

Pioglitazone and telmisartan in a formulation were estimated by RP-HPLC technique using 35\% of $0.5 \%$ triethylamine and $65 \%$ of acetonitrile [34]. High-performance thin-layer chromatography (HPTLC) technique was used for the estimation of metformin, glimepiride, and atorvastatin in fixed dosage combination using water:methanol:ammonium sulfate as mobile phase [35]. In a similar study, the determination of antidiabetic and antihypertensive drugs in pharmaceutical formulations was analyzed by RP-LC with Lichrocart $\mathrm{C}_{10}$ as a stationary phase and methanol:water:orthophosphoric acid (75:25:0.2) as mobile phase [36]. Simultaneous estimation of atorvastatin, metformin, and glimepride in the formulation was carried out by RP HPLC technique, and the separation was achieved by Hibar $\mathrm{C}_{18}$ as stationary phase using $40 \%$ of ACN and $60 \%$ ammonium acetate $(10 \mathrm{mM}, \mathrm{pH} 3.0$, adjusted using acetic acid) as eluent, respectively [37].

\section{CONCLUSION}

Chromatographic methods are considered to be rapid tools for qualitative and quantitative analysis of newer chemical entities in pharmaceuticals. In recent times, there were several new drug molecules that were introduced in to the market, but always there exists a lag in establishing a defined protocol for the analysis of impurities, their identification and the development of assay methods. Hence, this review attempts to collate various analytical techniques that were developed and validated for the estimation of few important antidiabetic and antihypertensive drugs either in pure, individually or combined with other pharmaceutical dosage form by HPLC, LC-MS/MS, and HPTLC techniques.

\section{ACKNOWLEDGMENTS}

The authors are thankful to the management of Vels Institute of Science, Technology and Advanced Studies (VISTAS), for providing the necessary library facilities, infrastructure, and equipments for carrying out the research work.

\section{AUTHORS' CONTRIBUTIONS}

The authors SV and HG had contributed equally towards the collection of literature and preparation of the manuscript.

\section{REFERENCES}

1. Tripathi KD. Essentials of Medical Pharmacology. Antihypertensive Drugs. $6^{\text {th }}$ ed. New Delhi: Jaypee Brother Medical Publishers (P) Ltd.; 2008. p. 539-54.

2. Satoskar RS, Bhandarkar SD, Nirmala N REGE. Pharmacology and Pharmacotherapeutics. Insulin and Oral Anti Diabetic Drugs. $19^{\text {th }}$ ed. Mumbai: Popular Prakashan; 2005. p. 871-900.

3. Katzung BG, Susan B, Anthony JT. Basic and Clinical Pharmacology. 11 ${ }^{\text {th }}$ ed. New York: Tata McGraw Hill Education Private Limited.; 2009. p. $167-87$.

4. Lin ZJ, Ji W, Desai-Krieger D, Shum L. Simultaneous determination of pioglitazone and its two active metabolites in human plasma by LC-MS/MS. J Pharm Biomed Anal 2003;33:101-8.

5. Karra VK, Rao PN, Inamadugu JK, Rao JS. Simultaneous determination of pioglitazone and candesartan in human plasma by LC-MS/MS and its application to a human pharmacokinetic study. J Pharm Anal 2012;2:167-73.

6. Zhang X, Ma J, Hu L, Zhang Q, Wang X, Pan J, et al. Simultaneous determination of tolbutamide and its metabolite hydroxytolbutamide in rat plasma by LC-MS. J Liq Chromatogr R T 2012;35:1627-37.

7. Reddy S, Ahmed I, Ahmad I, Mukhopadhyay A, Thangam S. Development and validation of a method for simultaneous estimation of metformin and sitagliptin in human plasma by LC-MS/MS and its application in a bioequivalence study. J Chromatogr Sci 2015;53:1549-56.

8. Polagani SR, Pilli NR, Gajula R, Gandu V. Simultaneous determination of atorvastatin, metformin and glimepiride in human plasma by LC-MS/MS and its application to a human pharmacokinetic study. J Pharm Anal 2013;3:9-19.

9. Ezzeldin E, Abo-Talib NF, Tammam MH, Shahat AA. Development and validation of LC-MS/MS method for the simultaneous determination of montelukast, gliclazide, and nifedipine and its application to a pharmacokinetic study. Chem Cent J 2014;8:17

10. Chunduri RH, Dannana GS. Development and validation of a reliable and rapid LC-MS/MS method for simultaneous quantification of sacubitril and valsartan in rat plasma and its application to a pharmacokinetic study. Biomed Chromatogr 2016;30:1467-75.

11. Elzanfaly ES, Abdel-Gawad SA. Simultaneous quantification of ramipril, glimepiride and metformin in human plasma by ultraperformance liquid chromatography-tandem mass spectrometry. J Appl Pharm Sci 2017;7:62-9.

12. Shah JV, Shah PA, Shah PV, Sanyal M, Shrivastav PS. Fast and sensitive LC-MS/MS method for the simultaneous determination of lisinopril and hydrochlorothiazide in human plasma. J Pharm Anal 2017;7:163-9.

13. Goryński K, Kiedrowicz A, Bojko B. Development of SPME-LC-MS method for screening of eight beta-blockers and bronchodilators in plasma and urine samples. J Pharm Biomed Anal 2016;127:147-55.

14. Sengupta P, Chatterjee B, Mandal UK, Gorain B, Pal TK. Development and validation of a high throughput LC-MS/MS method for simultaneous quantitation of pioglitazone and telmisartan in rat plasma and its application to a pharmacokinetic study. J Pharm Anal 2017;7:381-7

15. Chan-Mei LV, Chun-Min W, Fan-Long B, Chen R, Xiao-Lu W, Li R, et al. Determination of amlodipine in human plasma by LC-MS/MS and its bioequivalence study in healthy Chinese subjects. Pharmacol Pharm 2013;4:191-200.

16. Hotha KK, Yarramu NR, Kandibedala T, Dasari VB, Vobalaboina V. Simultaneous determination of atorvastatin and glimepiride by LC-MS/MS in human plasma and its application to a pharmacokinetic study. Am J Analyt Chem 2012;3:559-69.

17. Premanand DC, Senthilkumar KL, Senthilkumar B, Saravanakumar M, Thirumurthy R. A new RP-HPLC method development and validation 
for simultaneous estimation of telmisartan and pioglitazone in pharmaceutical dosage form. Int J Chemtech Res 2011;3:448-54.

18. Amin MM, Salah AA, Samia MM, Sobhy EM. Optimization and validation of HPLC method for simultaneous determination of vildagliptin, pioglitazone hydrochloride and glimepiride in bulk and tablets. IOSR J Pharm Biol Sci 2017;12:18-27.

19. Hossain K, Rahman A, Sultan Z, Islam F, Salam AA, Rashid AM. A validated RP-HPLC method for simultaneous estimation of antidiabetic drugs pioglitazone $\mathrm{HCl}$ and glimepiride. Bangladesh Pharm J 2013; 16:69-75.

20. Ibrahim M. Development and validation of a RP-HPLC method for the simultaneous determination of carvedilol, glimepiride or glibenclamide in binary combinations and its application for in vitro interaction studies. Indo Am J Pharm Res 2015;5:2792-802.

21. Regalla MR, Thaduvai VR. Method development and validation for simultaneous estimation of metformin, glimepiride and atorvastatin in combined tablet dosage form by UPLC. World J Pharm Pharm Sci 2013;2:5229-47.

22. Aseervadamma M, Sandeep A, Rajesh K, Babu VK, Pradeep M and Venkatesh S. Method development and validation for metformin and telmisartan in pure solid dosage form by using RP-HPLC method. Int J Pharm Pharm Anal 2017;1:1-6.

23. Priya VM, Madhavan P, Kumar P, Kumar R. RP-HPLC method for simultaneous estimation of metformin $\mathrm{HCl}$, ramipril and glimepiride in bulk and their combination tablet dosage form. IOSR J Pharm Biol Sci 2016;11:16-23.

24. Asthana S, Kaur V, Chawla P, Saraf S. Rapid and sensitive HPLC-UV method for simultaneous estimation of nifedipine, nateglinide and lovastatin: Quantitative application to polypill based synthetic ternary mixture. Int J Pharmtech Res 2010;2:682-8

25. Rahman MF, Sultan MZ, Rahman A, Rahman MA, Salam MA. Simultaneous estimation of antihypertensive and antidiabetic drugs by HPLC. Res Rev J Pharm Qual Assur 2015;1:25-9.

26. Sudesh BM, Uttamrao KS. Determination and validation of valsartan and its degradation products by isocratic HPLC. J Chem Metrol 2009;3:1-12

27. Sultana N, Naveed S, Arayne MS. Development and validation of a simple and efficient RPLC method for analysis of captopril, metformin, pioglitazone and glibenclamide in API, formulations and human serum. J Chromatogr Sep Technol 2013;4:7.

28. Porwal PK, Talele GS. Development of validated HPLC-UV method for simultaneous determination of metformin, amlodipine, glibenclamide and atorvastatin in human plasma and application to protein binding studies. Bull Fac Pharm Cairo Univ 2017;55:129-39.

29. Baranwal GJ, Upadhyay S, Tripathi AC, Saraf SK. Stability indicating RP-HPLC method for simultaneous estimation of anti-diabetic and anti-hypertensive drugs. Rasayan J Chem 2015;8:287-97.

30. Gayathri P, Jayaveera KN, Goud S, Reddy NS. Analytical method development and validation for the simultaneous estimation of metformin and telmisartan in bulk and pharmaceutical dosageforms using RP-HPLC method. World J Pharm Pharm Sci 2015;4:753-62.

31. Ramesh D, Habibuddin M. Stability indicating RP-HPLC method for the simultaneous determination of atorvastatin calcium, metformin hydrochloride, and glimepiride in bulk and combined tablet dosage form. Int Sch Res Notices 2014;2014:754695

32. Navaneetha S, Srinivas M. RP-HPLC method for the simultaneous estimation of metformin hydrochloride and telmisartan in bulk and in a synthetic mixture. Int J Chemtech Res 2014;6:4737-45.

33. Bello SS, Sani FB, Odunola MT, Garba M, Garba MA. Interaction of metformin and nifedipine in Type 2 diabetic patients with hypertension. J Chem Pharma Res 2017;9:103-7.

34. Kamalakannan D, Vijay AR, Kumar SN. Simultaneous estimation of telmisartan and pioglitazone in pharmaceutical dosage form by RP-HPLC method. Asian J Res Chem 2010;3:364-6.

35. Alagawadi KR, Kumar MA. HPTLC Method for the simultaneous estimation of atorvastatin, glimipride and metformin in combined dosage form. J Pharm Biomed Sci 2010;7:1-4.

36. Raghuwanshi AS, Upadhyay S, Saraf S, Shailendra S. Simultaneous determination of antidiabetic and antihypertensive drugs in pharmaceutical formulations by RP-LC. Int $\mathrm{J}$ Chemtech Res 2017; 10:287-97.

37. Ujwala C, Veni KN, Karthik Y, Gowramma B, Meyyanathan SN. Simultaneous determination of atorvastatin, metformin and glimepride in pharmaceutical dosage form by a stability indicating RP HPLC method. J Chem Pharm Res 2017;9:260-7. 